\title{
Limited predictive value of an acute test with subcutaneous octreotide for long-term IGF-I normalization with Sandostatin LAR in acromegaly
}

\author{
Wouter W de Herder, H Rob Taal, Piet Uitterlinden, Richard A Feelders, Joop A M J L Janssen \\ and Aart-Jan van der Lely \\ Section of Endocrinology, Department of Internal Medicine, Erasmus MC, Dr. Molewaterplein 40, 3015 GD Rotterdam, The Netherlands \\ (Correspondence should be addressed to WW de Herder; Email: w.w.deherder@erasmusmc.nl)
}

\begin{abstract}
Objectives: To study whether the growth hormone (GH) response after the subcutaneous administration $50 \mu \mathrm{g}$ of octreotide (acute octreotide test) has any predictive value for long-term IGF-I normalization with Sandostatin LAR.

Design: Twenty four therapy-naive patients with active acromegaly were studied.

Results: $>75 \%$ GH decrease in the acute octreotide test predicted long-term IGF-I normalization with Sandostatin LAR in 8/11 (73\%) of patients. 3/13 (23\%) patients with $<75 \%$ GH decrease in the acute octreotide test were long-term biochemically controlled with Sandostatin LAR. Using the $>75 \% \mathrm{GH}$ reduction criterion, the sensitivity and specificity of this test for predicting long-term normalization of serum IGF-I with Sandostatin LAR treatment were $73 \%$ and $77 \%$, respectively (positive and negative predictive values: $73 \%$ and $77 \%$, respectively). $6 / 8(75 \%)$ patients with $\mathrm{GH}$ suppression to levels $<1.1 \mu \mathrm{g} / \mathrm{l}$ and 9/16 (56\%) patients with GH suppression to levels $<2 \mu \mathrm{g} / \mathrm{l}$ in the acute octreotide test showed normalization of serum IGF-I with long-term Sandostatin LAR treatment. The sensitivity and specificity of GH suppression $<1.1 \mu \mathrm{g} / \mathrm{l}$ for predicting of the long-term normalization of serum IGF-I with Sandostatin LAR therapy were $55 \%$ and $85 \%$, respectively (positive and negative predictive values: $75 \%$ and $69 \%$, respectively). The sensitivity and specificity of GH suppression $<2 \mu \mathrm{g} / \mathrm{l}$ for predicting of the long-term normalization of serum IGF-I with Sandostatin LAR therapy were $82 \%$ and $46 \%$, respectively (positive and negative predictive values: $56 \%$ and $75 \%$, respectively).

Conclusion: The acute octreotide is not recommended for clinical decision making with regard to longterm treatment using the long-acting somatostatin analog Sandostatin LAR in acromegaly.
\end{abstract}

European Journal of Endocrinology 153 67-71

\section{Introduction}

Acromegaly is a chronic and debilitating disorder, which is almost uniquely caused by growth hormone (GH) hypersecretion from a pituitary adenoma (1). Serum insulin-like growth factor I (IGF-I) has been used both as a screening tool and as a tool for clinical monitoring of therapeutic response in patients with acromegaly (2).

Historically, pituitary surgery has been used as firstline treatment for acromegaly. With this treatment, cure rates have been the greatest for microadenomas (ranging from 70 to $80 \%$ ), but for macroadenoma surgery success rates less than $50 \%$ have been reported (3).

Nowadays, medical treatment for acromegaly consists of dopamine agonists, somatostatin analogs, $\mathrm{GH}$ receptor antagonists or combinations. Long-acting somatostatin analogs are increasingly being appreciated as first-line therapies for active acromegaly especially for those patients in whom an operation will not likely result in complete cure or in those patients with contraindications for operation (4-7). In the past, acute tests have been designed for predicting the long-term response of the tumoral GH secretion to short-acting somatostatin analogs. Whether acute tests adequately predict these long-term responses is debatable $(8-10)$. The potential predictive value of acute tests for the long-term response to long-acting depot formulations of somatostatin analogs has only been studied very recently by Karavitaki and coworkers (11). In their studies, an acute octreotide test was reliable in predicting 'safe' $\mathrm{GH}$ levels in patients treated with long-acting octreotide (Sandostatin LAR), 
although it was less reliable for predicting this on longacting lanreotide (Somatulin Autogel, or Somatuline LA).

In the present study we have determined whether an acute test using a single subcutaneous dose of octreotide is useful for predicting long-term normalization of serum IGF-I levels with Sandostatin LAR.

\section{Patients and methods}

\section{Patients}

Twenty four patients (13 females, 11 males, 24-79 years old at diagnosis, mean age at diagnosis 56 years) with active acromegaly were enrolled in these studies. The diagnosis of active acromegaly was made on the basis of typical clinical features and/or non-suppressed GH after an oral glucose load and IGF-I levels above the age- and sex-adjusted reference range of the assay and the presence of a pituitary tumor at neuroradiology. The patients had not previously been treated with somatostatin analogs, nor with dopamine agonists or $\mathrm{GH}$ receptor antagonists and were not operated upon nor had received pituitary radiotherapy. They were treated with Sandostatin LAR (Novartis Pharma, Basle, Switzerland) administered intramuscularly in dosages ranging from 10-30 mg every 4 weeks. The dosage was titrated until the maximum dosage of $30 \mathrm{mg}$ Sandostatin LAR per month was reached, or until normalization of serum IGF-I levels was achieved. Patients were maintained on Sandostatin LAR treatment for at least 9 months. All patients gave their informed consent to participate in these studies.

\section{Test protocol and follow-up}

Fifty micrograms of octreotide was administered subcutaneously and blood samples were drawn for $\mathrm{GH}$ measurements at $15 \mathrm{~min}$ before and 15, 45, 105, $165,225,285,345,405$ and $465 \mathrm{~min}$ after administration of the drug. On a control day, samples for $\mathrm{GH}$ measurements were drawn at the same time intervals, but no drug was administered. The response to octreotide was calculated using the mean of the 45-465 min $\mathrm{GH}$ measurements or mean 45-225 min measurements. GH measurements and expressed as percentage of the GH measurements over the same time interval on the control day. As defined previously, a positive $\mathrm{GH}$ response in this test had been arbitrarily defined as $>75 \%$ decrease of the mean $45-465 \mathrm{~min}$ or 45-225 min GH levels (12). We also have looked at a less stringent $\mathrm{GH}$ decrease amounting to more than $50 \%$. The $\mathrm{GH}$ nadir response was also evaluated.

For long-term follow-up, serum IGF-I was used as parameter for biochemical control. Gender- and age-dependent cut-off levels, as supplied by the manufacturers of the assay, were used.

\section{Assays}

Serum GH levels were measured by a two-site chemiluminescent immunometric assay (Immulite; Diagnostic Products Corp., Los Angeles, CA, USA) (intra-assay CV $6.0 \%$, inter-assay CV 5.7\%). Serum IGF-I levels were measured by a non-extraction immunometric assay supplied by Diagnostic Systems Laboratories Inc. (Webster, TX, USA) (intra-assay CV 3.9\%, interassay CV $4.2 \%$ ).

\section{Results}

\section{Patients and GH and IGF-I levels}

In the 24 patients, basal serum GH levels were $19.0 \pm 26.6 \mu \mathrm{g} / \mathrm{l}$ (mean \pm s.D.), serum GH levels were $18.3 \pm 20.2 \mu \mathrm{g} / \mathrm{l}$ (mean \pm S.D.) in the $45-465 \mathrm{~min}$ sampling interval and 18.0 $\pm 20.2 \mu \mathrm{g} / \mathrm{l}$ (mean \pm s.D.) in the 45-225 min sampling interval, both on a control day. Mean basal serum IGF-I levels were $153.6 \mathrm{nmol} / \mathrm{l}$. Overall, in 11 out of these 24 patients (46\%), serum IGF-I levels normalized with Sandostatin LAR therapy at long-term ( $>9$ months) follow-up.

\section{Acute octreotide test and long-term follow-up}

Sampling intervals and GH decrease after octreotide Eleven of the 24 patients (46\%) showed $>75 \%$ GH decrease in the acute octreotide test within the 45-465 min, or 45-225 min GH sampling intervals. At follow-up, eight out of these 11 patients $(73 \%)$ showed an adequate suppression of serum IGF-I to levels within the reference range with longterm Sandostatin LAR treatment.

Thirteen out of the 24 patients (54\%) did not show $>75 \%$ GH response in the acute octreotide test. Three out of these 13 patients (23\%) showed normalization of serum IGF-I with long-term Sandostatin LAR treatment.

Using the $>75 \% \mathrm{GH}$ reduction criterion, the acute octreotide test had a sensitivity of $73 \%$ and a specificity of $77 \%$ for predicting long-term normalization of serum IGF-I with Sandostatin LAR treatment. Results were similar for both $\mathrm{GH}$ sampling intervals (45-465 min or 45-225 min GH sampling). Using this criterion, the positive predictive value of the acute octreotide test for the long-term normalization of serum IGF-I with Sandostatin LAR treatment was $73 \%$ and the negative predictive value was $77 \%$ (Table 1 ).

Nineteen out of the 24 patients (79\%) showed $>50 \%$ decrease in the acute octreotide test within the 45-465 min GH sampling interval and 20 patients (83\%) within the 45-225 min GH sampling interval. At follow-up, 11 of these patients $(58 \%$ of patients with the 45-465 min GH sampling interval, or $55 \%$ of patients with the $45-225 \mathrm{~min}$ GH sampling interval) showed an adequate suppression of serum 
Table 1 The acute $50 \mu \mathrm{g}$ octreotide test. Prognostic profiles (\%) of various GH suppression values.

\begin{tabular}{|c|c|c|c|c|c|c|}
\hline & $\begin{array}{c}45-465 \text { min GH } \\
\text { suppression } \\
>75 \%\end{array}$ & $\begin{array}{c}45-225 \text { min GH } \\
\text { suppression } \\
>75 \%\end{array}$ & $\begin{array}{c}45-465 \text { min GH } \\
\text { suppression } \\
>50 \%\end{array}$ & $\begin{array}{c}45-225 \text { min GH } \\
\text { suppression } \\
>50 \%\end{array}$ & $\begin{array}{l}\text { GH nadir } \\
<1.1 \mu \mathrm{g} / \mathrm{l}\end{array}$ & $\begin{array}{l}\text { GH nadir } \\
<2 \mu \mathrm{g} / \mathrm{l}\end{array}$ \\
\hline Sensitivity & 73 & 73 & 100 & 100 & 55 & 82 \\
\hline Specificity & 77 & 77 & 38 & 31 & 85 & 46 \\
\hline $\begin{array}{l}\text { Positive } \\
\text { predictive value }\end{array}$ & 73 & 73 & 58 & 55 & 75 & 56 \\
\hline $\begin{array}{l}\text { Negative } \\
\text { predictive value }\end{array}$ & 77 & 77 & 100 & 100 & 69 & 75 \\
\hline
\end{tabular}

IGF-I to levels within the reference range with Sandostatin LAR.

Five out of the 24 patients $(21 \%)$ did not show $>50 \%$ GH decrease in the acute octreotide test within the 45-465 min GH sampling interval and four patients $(17 \%)$ within the $45-225 \mathrm{~min} \mathrm{GH}$ sampling interval. None of these patients showed normalization of serum IGF-I with long-term Sandostatin LAR treatment.

Using the $>50 \% \mathrm{GH}$ reduction criterion, the acute octreotide test had a sensitivity of $100 \%$ and a specificity of $38 \%$ for predicting long-term normalization of serum IGF-I with Sandostatin LAR therapy for the 45-465 min GH sampling period. For the 45-225 min GH sampling period, these values were $100 \%$ and $31 \%$ respectively. Using this criterion, the positive predictive value of the acute octreotide test for the long-term normalization of serum IGF-I with Sandostatin LAR therapy was $58 \%$ for the 45-465 min GH sampling period and 55\% for the 45-225 min GH sampling period and the negative predictive value was $100 \%$ for both sampling periods (Table 1).

GH nadir after octreotide The nadir GH levels in the acute octreotide test were $5.1 \pm 11.9 \mu \mathrm{g} / \mathrm{l}$ (mean \pm S.D.), range $0.2-58.9 \mu \mathrm{g} / \mathrm{l}$ with a percentage decrease of $74 \%$ as compared with baseline $\mathrm{GH}$ levels. The time to achieve nadir was $142 \pm 99 \mathrm{~min}$ (mean \pm s.D.).

In the acute octreotide test, GH suppression to levels $<1.1 \mu \mathrm{g} / \mathrm{l}$ was achieved in eight out of 24 patients $(33 \%)$. six out of these eight patients (75\%) showed normalization of serum IGF-I with long-term Sandostatin LAR treatment, whereas two $(25 \%)$ did not. This level of $\mathrm{GH}$ suppression $(\mathrm{GH}<1.1 \mu \mathrm{g} / \mathrm{l})$ had a sensitivity of $55 \%$ and a specificity of $85 \%$ for predicting of the long-term normalization of serum IGF-I with Sandostatin LAR therapy. The positive and negative predictive values were $75 \%$ and $69 \%$ respectively (Table 1 ).

Less stringent GH suppression to levels $<2 \mu \mathrm{g} / \mathrm{l}$ in the acute octreotide test was achieved in 16 out of 24 patients $(66 \%)$. Nine out of these 16 patients $(56 \%)$ showed normalization of serum IGF-I with long-term Sandostatin LAR treatment, whereas seven (44\%) did not. This level of GH suppression $(\mathrm{GH}<2 \mu \mathrm{g} / \mathrm{l})$ had a sen- sitivity of $82 \%$ and a specificity of $46 \%$ for predicting of the long-term normalization of serum IGF-I with Sandostatin LAR therapy. The positive and negative predictive values were $56 \%$ and $75 \%$ respectively (Table 1 ).

\section{Discussion}

Historically, pituitary (sub)total adenomectomy used to be the primary treatment for active acromegaly. In the late sixties and early seventies of the past century, dopamine agonists were introduced for the medical treatment of prolactinomas and GH-secreting adenomas $(1,13)$. In the early eighties of the same century, octreotide was introduced as medical treatment for acromegaly, either as primary treatment or as adjunctive treatment after unsuccessful surgery. Because of their superiority to dopamine agonists, somatostatin analogs are currently considered as the first-line medical treatment of acromegaly $(1,14,15)$. Recently, the $\mathrm{GH}$ receptor blocking drug pegvisomant has been introduced for the treatment of those patients with acromegaly who are not responsive to somatostatin analogs or are intolerant to these drugs $(16,17)$.

Many studies have evaluated the effects of somatostatin analogs in active acromegaly $(5,18-32)$. The different criteria, which have been used to define the response to medical treatment, make it almost impossible to compare these studies. Also, newer, more sensitive GH and IGF-I assay techniques have been introduced over time. Suppression of GH to levels below 2.5, 2.0 and $1.0 \mu \mathrm{g} / \mathrm{l}$ have been used as criteria for sufficient response to medical treatment $(22,33)$. In our study, only normalization of serum IGF-I was used as the sole indicator of chronic control with medical treatment.

In previous studies, the long-term efficacy of shortacting and long-acting somatostatin analogs in sufficiently suppressing $\mathrm{GH}$ levels and/or normalizing IGF-I levels varied from 38 to $79 \%(5,19,21,24-32)$. However, in some of these studies, patients treated with long-acting somatostatin analogs had been selected on the basis of a positive response to short-acting analogs $(5,21,28)$. In our series of unselected therapy-naive patients, $46 \%$ of patients were controlled with Sandosta- 
tin LAR at long-term follow-up, as monitored by normalization of serum IGF-I.

In the present study, more than 75\% GH suppression in the acute octreotide test had a sensitivity of $73 \%$ and a specificity of $77 \%$ for predicting normalization of serum IGF-I with Sandostatin LAR therapy (positive predictive value $73 \%$, negative predictive value $77 \%$ ). As could be expected, using less stringent GH suppression $(>50 \%)$ in this test resulted in an increased sensitivity but decreased specificity (sensitivity 100\%, specificity $31-38 \%$, positive predictive value $55-$ $58 \%$, negative predictive value $100 \%$ ).

Twenty three percent of patients who demonstrated $<75 \%$ GH response, but none of the patients who demonstrated $<50 \%$ GH response to the acute administration to octreotide long term showed normalization of serum IGF-I with long-term Sandostatin LAR therapy.

In a study by Colao and co-workers, the sensitivity and specificity of an acute octreotide test for the long-term control by subcutaneously administered octreotide were $71 \%$ and $55 \%$, respectively (9). In this study, response was defined as GH-suppression to serum levels $<5 \mu \mathrm{g} / \mathrm{l}$ at follow-up. The positive and negative predictive values for the acute octreotide test in their study were 53\% and $78 \%$ respectively (9). In a recent study by Karavitaki and co-workers, the positive predictive value for an acute octreotide test for normalization of serum IGF-I was $60 \%$ for Somatuline Autogel, or Somatuline LA and $77 \%$ for Sandostatin LAR when suppression of GH levels in the acute test to $<6.05 \mathrm{mU} / \mathrm{l}$ and $<5.25 \mathrm{mU} / \mathrm{l}$ respectively, was used as criterion (11).

The mean nadir GH level in the acute octreotide test in these studies were $2.5 \mathrm{mU} / \mathrm{l}$ (percentage decrease $85 \%$ ), which compares well with our mean value amounting to $5.1 \mu \mathrm{g} / \mathrm{l}$ (percentage decrease $74 \%$ ). The mean time to achieve GH nadir in the study by Karavitaki and co-workers was $228 \mathrm{~min}$ (11) and in our studies it was $142 \mathrm{~min}$.

In conclusion, the acute octreotide test generally predicts the long-term biochemical response to Sandostatin LAR. However, also $23 \%$ of the patients who demonstrated less than $75 \%$ decrease in GH levels to the acute administration to octreotide, or $31 \%$ of the patients who did not demonstrate $\mathrm{GH}$ suppression to levels $<1.1 \mu \mathrm{g} / \mathrm{l}$, or $25 \%$ of the patients who did not demonstrate GH suppression to levels $<2 \mu \mathrm{g} / \mathrm{l}(25 \%)$ were still chronically controlled with Sandostatin LAR. Like other authors (9), we do not recommend acute octreotide tests. Whether this recommendation also holds for acute tests with newer (receptor specific, or universal) somatostatin analogs cannot be derived from the present study.

\section{References}

1 Melmed S, Casanueva FF, Cavagnini F, Chanson P, Frohman L, Grossman A, Ho K, Kleinberg D, Lamberts S, Laws E, Lombardi G, Vance ML, von Werder K, Wass J \& Giustina A.
Guidelines for acromegaly management. Journal of Clinical Endocrinology and Metabolism 200287 4054-4058.

2 van der Lely AJ, de Herder WW, Janssen JA \& Lamberts SW. Acromegaly: the significance of serum total and free IGF-I and IGFbinding protein-3 in diagnosis. The Journal of Endocrinology 1997155 (Suppl 1) S9-S13.

3 Melmed S, Jackson I, Kleinberg D \& Klibanski A. Current treatment guidelines for acromegaly. Journal of Clinical Endocrinology and Metabolism $1998 \mathbf{8 3} 2646-2652$.

4 Gilbert J, Ketchen M, Kane P, Mason T, Baister E, Manoghan M, Barr S \& Harris PE. The Treatment of De Novo Acromegalic Patients with Octreotide-LAR: Efficacy, Tolerability and Cardiovascular Effects. Pituitary 20036 11-18.

5 Bevan JS, Atkin SL, Atkinson AB, Bouloux PM, Hanna F, Harris PE, James RA, McConnell M, Roberts GA, Scanlon MF, Stewart PM, Teasdale E, Turner HE, Wass JA \& Wardlaw JM. Primary medical therapy for acromegaly: an open, prospective, multicenter study of the effects of subcutaneous and intramuscular slow-release octreotide on growth hormone, insulin-like growth factor-I, and tumor size. Journal of Clinical Endocrinology and Metabolism 200287 4554-4563.

6 Sheppard MC. Primary medical therapy for acromegaly. Clinical Endocrinology 200358 387-399.

7 Freda PU \& Wardlaw SL. Primary medical therapy for acromegaly. Journal of Clinical Endocrinology and Metabolism $1998 \mathbf{8 3}$ 3031-3033.

8 Lamberts SW, Uitterlinden P, Schuijff PC \& Klijn JG. Therapy of acromegaly with sandostatin: the predictive value of an acute test, the value of serum somatomedin-C measurements in dose adjustment and the definition of a biochemical 'cure'. Clinical Endocrinology 198829 411-420.

9 Colao A, Ferone D, Lastoria S, Marzullo P, Cerbone G, Di Sarno A, Longobardi S, Merola B, Salvatore M \& Lombardi G. Prediction of efficacy of octreotide therapy in patients with acromegaly. Journal of Clinical Endocrinology and Metabolism $1996 \mathbf{8 1}$ 2356-2362.

10 Pieters GFFM, Smals AGH \& Kloppenborg PWC. Long-term treatment of acromegaly with the somatostatin analogue SMS 201-995. The New England Journal of Medicine $1986 \mathbf{3 1 4}$ 1390-1392.

11 Karavitaki N, Botusan I, Radian S, Coculescu M, Turner HE \& Wass JA. The value of an acute octreotide suppression test in predicting long-term responses to depot somatostatin analogues in patients with active acromegaly. Clinical Endocrinology 200562 $282-288$.

12 van der Hoek J, de Herder WW, Feelders RA, van der Lely AJ, Uitterlinden P, Boerlin V, Bruns C, Poon KW, Lewis I, Weckbecker G, Krahnke T, Hofland LJ \& Lamberts SW. A singledose comparison of the acute effects between the new somatostatin analog SOM230 and octreotide in acromegalic patients. Journal of Clinical Endocrinology and Metabolism 200489 638-645.

13 Ferone D, Colao A, van der Lely AJ \& Lamberts SW. Pharmacotherapy or surgery as primary treatment for acromegaly? Drugs \& Aging 200017 81-92.

14 van der Lely AJ, de Herder WW \& Lamberts SW. A risk-benefit assessment of octreotide in the treatment of acromegaly. Drug Safety 199717 317-324.

15 van der Lely AJ, de Herder WW \& Lamberts SW. New medical treatment for acromegaly. Pituitary 19992 89-92.

16 van der Lely AJ, Hutson RK, Trainer PJ, Besser GM, Barkan AL, Katznelson L, Klibanski A, Herman-Bonert V, Melmed S, Vance ML, Freda PU, Stewart PM, Friend KE, Clemmons DR, Johannsson G, Stavrou S, Cook DM, Phillips LS, Strasburger CJ, Hackett S, Zib KA, Davis RJ, Scarlett JA \& Thorner MO. Longterm treatment of acromegaly with pegvisomant, a growth hormone receptor antagonist. Lancet 2001358 1754-1759.

17 Paisley AN, Trainer PJ \& Drake WM. The place of pegvisomant in the acromegaly treatment algorithm. Growth Hormone and IGF Research 200414 (Suppl A) S101-S106. 
18 Lamberts SW, van der Lely AJ, de Herder WW \& Hofland LJ. Octreotide. The New England Journal of Medicine 1996334 246-254.

19 Newman CB, Melmed S, George A, Torigian D, Duhaney M, Snyder P, Young W, Klibanski A, Molitch ME, Gagel R, Sheeler L, Cook D, Malarkey W, Jackson I, Vance ML, Barkan A, Frohman L \& Kleinberg DL. Octreotide as primary therapy for acromegaly. Journal of Clinical Endocrinology and Metabolism $1998 \mathbf{8 3}$ 3034-3040.

20 Burt MG \& Ho KK. Comparison of efficacy and tolerability of somatostatin analogs and other therapies for acromegaly. Endocrine 200320 299-305.

21 Morange I, De Boisvilliers F, Chanson P, Lucas B, Dewailly D, Catus F, Thomas F \& Jaquet P. Slow release lanreotide treatment in acromegalic patients previously normalized by octreotide. Journal of Clinical Endocrinology and Metabolism 199479 145-151.

22 Freda PU. Somatostatin analogs in acromegaly. Journal of Clinical Endocrinology and Metabolism 200287 3013-3018.

23 Attanasio R, Barausse M \& Cozzi R. GH/IGF-I normalization and tumor shrinkage during long-term treatment of acromegaly by lanreotide. Journal of Endocrinological Investigation $2001 \mathbf{2 4}$ 209-216.

24 Cozzi R, Attanasio R, Montini M, Pagani G, Lasio G, Lodrini S, Barausse M, Albizzi M, Dallabonzana D \& Pedroncelli AM. Fouryear treatment with octreotide-long-acting repeatable in 110 acromegalic patients: predictive value of short-term results? Journal of Clinical Endocrinology and Metabolism 200388 3090-3098.

25 Lancranjan I \& Atkinson AB. Results of a European multicentre study with Sandostatin LAR in acromegalic patients. Sandostatin LAR Group. Pituitary 19991 105-114.

26 Newman CB, Melmed S, Snyder PJ, Young WF, Boyajy LD, Levy R, Stewart WN, Klibanski A, Molitch ME \& Gagel RF. Safety and efficacy of long-term octreotide therapy of acromegaly: results of a multicenter trial in 103 patients - a clinical research center study. Journal of Clinical Endocrinology and Metabolism $1995 \mathbf{8 0}$ 2768-2775.

27 Stewart PM, Kane KF, Stewart SE, Lancranjan I \& Sheppard MC. Depot long-acting somatostatin analog (Sandostatin-LAR) is an effective treatment for acromegaly. Journal of Clinical Endocrinology and Metabolism $1995 \mathbf{8 0} 3267-3272$.

28 Caron P, Cogne M, Gusthiot-Joudet B, Wakim S, Catus F \& Bayard F. Intramuscular injections of slow-release lanreotide (BIM 23014) in acromegalic patients previously treated with continuous subcutaneous infusion of octreotide (SMS 201-995). European Journal of Endocrinology 1995132 320-325.

29 Giusti M, Gussoni G, Cuttica CM \& Giordano G. Effectiveness and tolerability of slow release lanreotide treatment in active acromegaly: six-month report on an Italian multicenter study. Italian Multicenter Slow Release Lanreotide Study Group. Journal of Clinical Endocrinology and Metabolism 199681 2089-2097.

30 Flogstad AK, Halse J, Bakke S, Lancranjan I, Marbach P, Bruns C \& Jervell J. Sandostatin LAR in acromegalic patients: long-term treatment. Journal of Clinical Endocrinology and Metabolism 1997 82 23-28.

31 Marek J, Hana V, Krsek M, Justova V, Catus F \& Thomas F. Longterm treatment of acromegaly with the slow-release somatostatin analogue lanreotide. European Journal of Endocrinology 1994131 $20-26$.

32 Davies PH, Stewart SE, Lancranjan L, Sheppard MC \& Stewart PM. Long-term therapy with long-acting octreotide (Sandostatin-LAR) for the management of acromegaly. Clinical Endocrinology 1998 $48311-316$.

33 Freda PU. How effective are current therapies for acromegaly? Growth Hormone and IGF Research 200313 S144-S151.

Received 28 February 2005

Accepted 22 March 2005 